Please cite: Clarke, K., Holt, A., Norris, C., \& Nel, P. W. (2017). Adolescent-to-parent violence and abuse: Parents' management of tension and ambiguity-an interpretative phenomenological analysis. Child \& Family Social Work.

\title{
Adolescent-to-parent violence and abuse: Parents' management of tension and ambiguity-an interpretative phenomenological analysis.
}

\begin{abstract}
Adolescent violence and abuse towards parents is under researched, especially in the UK where reports of the phenomenon are increasing with little clear guidance as to how practitioners might respond. In this qualitative study, six parents were recruited through Youth Offending Teams and were interviewed about their lived experiences of violence and/or abuse from their adolescent child. Using Interpretative Phenomenological Analysis (IPA), three superordinate themes emerged: (1) the tensions and (2) the ambiguities produced by living with the violence and abuse, and (3) the ways that parents manage the harms caused by these tensions and ambiguities. Theoretical and clinical implications are discussed, including consideration of how practitioners might support parents who are living with APVA to establish healthy and sustainable coping strategies while repairing family relationships.
\end{abstract}

Keywords: child, adolescent, parent, violence, domestic violence, abuse, Interpretative Phenomenological Analysis 
Introduction

'Adolescent-to-parent violence and abuse' (APVA) refers to a persistent pattern of abuse that enables young people to assert power and control over their parent(s). Adolescent development occurs between the ages of 12 and 24 years (Bobic, 2004) and spans the statutory transition from childhood into adulthood (i.e. over 18 years, Home Office, 2015). Adolescent abuse tactics may be verbal, emotional, financial and/or physical. As common to all abuse, the evocation of shame among victims makes it difficult for support services to identify and respond to it and, as such, it is difficult to estimate its prevalence. In the UK, a recent study analysed data from the Metropolitan Police Service and identified 1,892 reports of violence towards parents in one year (2009-2010) (Condry \& Miles 2013). Furthermore, an increase in reports of adolescent violence towards parents has been identified by Family Lives, the national family support service (Family Lives, 2011) and by the Director of Public Prosecutions (Bentham, 2013). However, it is outside the UK where greater empirical advances have been made in this field. For example, a comprehensive study in Canada triangulated reports of violence from parents and their children, and distinguished different forms of abuse and its gendered impact. Over a six-month period, this study found prevalence rates of $13.8 \%$ of physical aggression against mothers and $11 \%$ towards fathers; and $64 \%$ of verbal aggression towards mothers and $56 \%$ towards fathers (Pagani, 2004; 2009). Such rates indicate impact for parents irrespective of gender guiding the present research to include either parent. Prevalence rates have also been identified in the United States (e.g., see Agnew \& Huguley, 1989), Germany (e.g., see DuBois, 1998) and Spain (e.g., Calvete, Gámez-Guadix \& Orue, 2014), though all such prevalence studies are subject to methodological limitations in relation to sample populations, definitional criteria and measuring instruments (see Holt, 2012 for a critical review), requiring research to remain sensitive to phenomenological nuances as achievable the need for single case focus.

In the UK, researchers and family support practitioners such as youth offending teams and domestic violence workers have campaigned to draw attention to this problem. Several practice-focussed texts have been published (e.g., Downey \& Furnish 2015; Holt, 2016) and the UK government published its first guidance document for frontline practitioners who are required to provide a first response to what the UK government terms 'adolescent-toparent violence and abuse' (APVA) (Home Office, 2015). Yet despite these developments, progress is slow and there remains little consensus as to how practitioners might define, discuss, detect, record and report APVA, hindering the extent that the phenomenon can be understood and appropriately addressed The paper presented here addresses this knowledge gap by examining the lived experiences of seven parents who are experiencing APVA and who described their experiences through qualitative interviews.

Researching parents' experiences of adolescent-to-parent violence and abuse

International research has found that APVA causes both acute and enduring harm to individuals and families. For parents, this includes physical and mental health problems, including depression, anxiety and suicide ideation, and damage to relationships with other family members and communities. It may also impact on work and personal finances (see Holt, 2013 for a review). For the instigators and their siblings, there is evidence of increasing isolation and greater risk of further offending behaviour (Laurent \& Derry, 1999), including subsequent violence towards dating partners (LaPorte et al. 2009) and marriage partners 
(O'Leary et al. 2004). Parents experience multiple types of abuse that may be physical, mental and/or emotional and which have profound impacts on their life worlds. Verbal abuse is often the first kind of abuse to appear and while it is often overlooked or regarded as trivial, it may escalate into emotional, financial and/or physical violence over time (Cottrell \& Monk, 2004; Eckstein, 2004; Jackson, 2003). Such range and interrelation of harm suggests experiences are multiple and varied requiring further understanding at a parentby-parent level.

Parents often attempt to challenge or resist the abuse, but if such attempts fail, parents instead try to merely contain the abuse, resulting in increased insularity and consequent are at greater risk of harm from their own child (Holt, 2011). Isolation is commonly reported, with parents describing a sense of imprisonment at home alongside a continual fear of further abuse and violence that is silenced by a culture of shame and blame (Bobic 2004; Howard \& Rottem 2008; Holt, 2011; Laing 2014). Shame and blame are central to experiences of APVA because of what Holt (2013: 5) terms a 'double stigma' in that APVA intersects the stigma of parenting a problematic child (Jackson \& Mannix 2004) and of the stigma of experiencing abuse in the home (Stanko, 2003). Furthermore, the sense of entrapment, which is common to many abusive experiences, is exacerbated by the 'parental responsibility' that parents legally have over their children (see Children Act 1989). This makes legal remedies such as leaving the family home, or removing the child from the home, impractical (Hunter \& Piper, 2012). Even contacting the police to report a child's violence is problematic, since parents can also be held criminally responsible for the offences of their child (see Crime and Disorder Act, 1998). Such actions have produced perverse consequences, such as parents being forced to pay for the fines imposed on their child in response to their own victimisation (Holt \& Retford, 2013; Nixon, 2012). In terms of help-seeking, research suggests that parents find little support from friends and family, who often trivialise the problem and/or blame the parent themselves for their child's violence. Consequently, parents seek support from outside agencies, most commonly from the child's school, GP, CAMHS (Child and Adolescent Mental Health Services), social services and the police (Parentline Plus, 2010) who thus are ideally placed for identifying parents at risk or experiencing harm. However, existing research suggests that such institutional awareness and responses are patchy and, in some cases, may be counter-productive, ultimately increasing parents' sense of hopelessness and despair (Cottrell \& Monk, 2004; Holt, 2011).

The past decade has seen a small but significant increase in qualitative research in this field. Most commonly the data have come from interviews with parents who self-identified as parent-victims and who attended reparative parenting support programmes (e.g., Paterson et al. 2002; Gallagher, 2004; Cottrell, 2005). A small number of studies have attempted to access non-clinical populations - those who have not sought help - through secondary analysis of parenting surveys (Jackson, 2003) and online message-boards (Holt, 2011). While useful in accessing this distinct population, such studies do not allow the researcher to explore the nature, contours and lived experience of APVA with the parent. An alternative method is to access parents who have not actively sought help but whose experiences of APVA have come to the attention of agencies who they are involved with, most commonly Youth Offending Teams (YOTs) who work with the parents of young offenders. In the UK, there is a small body of research that has used this method (e.g., Holt, 2009; Condry \& Miles, 2012). While the current study also utilises this sampling method, it is the first UK study to use an Interpretive Phenomenological analysis (IPA) (Smith, Flowers \& Larkin, 2009) 
to explore how parents construct their lived experiences of APVA and how they interact with their world. Given the existing lack of knowledge about how parents understand and make sense of APVA from their own lived experience, this article adopts a stance of openness and curiosity with the focuses on gaining a yet unexplored, in-depth, detailed appreciation of what it is like for parents to experience violence and abuse from their adolescent children with the aim of enabling practitioners to understand more clearly how living with APVA is experienced, and how/why parents respond as they do.

\section{Methodology}

The research was conducted via three Youth Offending Teams (YOT's) in Southern England who expressed interest and who identified cases of parent abuse within their caseloads. YOT's are local authority council led multi-disciplinary agencies which engage with young people who have offended or who are identified as 'at risk' of offending (UK Government, 2014). YOT professionals are well positioned to identify cases of APVA through primary accounts (i.e. disclosures from parents or young people) and secondary accounts (i.e., through police reports) and thus provide a homogenous baseline of families. The research project was described to YOT gatekeepers and parents as an opportunity to speak about the experiences of parents whose children have behaved violently and/or abusively towards them.

Five mothers and one father took part in the study. This sample reflects both the reported gendered nature of the phenomenon (Condry \& Miles, 2013) and, relatedly, the ways in which mothers tend to volunteer to participate in social research that concerns parenting and family life (Phares, 1992). Geographical location of participants along with the following limited descriptions of their backgrounds allows the reader a sufficient understanding of the parents' contexts against the overriding priority of preserving anonymity. Pseudonyms are used throughout and contexts are sufficiently common that identification of real names is not possible and only exists in securely stored documents. All parents described themselves as White British. Their child's age ranged between 14 and 23 years (modal age 16 years). One parent described themselves as having a physical disability and three parents were diagnosed by their GP with depression and were taking prescribed antidepressants. Two parents (Denise and Richard) were married to each other and each was interviewed separately. Three parents lived with their identified child while three parents lived apart from their child (i.e. their child lived with extended family, friends or in a hostel) though maintained contact. Socio-demographic characteristics are summarised in Table 1 to familiarise the reader with each parent (parents' names are pseudonyms):

\begin{tabular}{l|l|l|l|l|l|}
\hline Parent & \multicolumn{1}{l}{$\begin{array}{l}\text { Parent Gender } \\
\text { identity }\end{array}$} & $\begin{array}{l}\text { Parent's age } \\
\text { (years) }\end{array}$ & $\begin{array}{l}\text { Child's age } \\
\text { (years) \& gender }\end{array}$ & $\begin{array}{l}\text { Parent relationship } \\
\text { identity }\end{array}$ & \multicolumn{2}{c}{$\begin{array}{l}\text { Living with } \\
\text { Child }\end{array}$} \\
\hline Jenny & $\begin{array}{l}\text { Female } \\
\text { (Mother) }\end{array}$ & 40 & 16y Female & Separated & Yes \\
\hline Tanya & Female & 45 & 23y Male & Single parent & \\
\hline
\end{tabular}




\begin{tabular}{|l|l|l|l|l|l|}
\hline & (Mother) & & & & \\
\hline Helen & $\begin{array}{l}\text { Female } \\
\text { (Mother) }\end{array}$ & 50 & 14 y Male & Divorced, Remarried & Yes \\
\hline Tina & $\begin{array}{l}\text { Female } \\
\text { (Mother) }\end{array}$ & 44 & $16 y$ Male & Single parent & Yes \\
\hline Denise & $\begin{array}{l}\text { Female } \\
\text { (Mother) }\end{array}$ & 46 & $18 y$ Male & Married (to Richard) & No \\
\hline Richard & Male (Father) & 48 & $18 y$ Male & Married (to Denise) & No \\
\hline
\end{tabular}

Table 1. Participant characteristics

Data collection and analysis

IPA (Smith et al. 2009) is a qualitative research method that is primarily used by researchers in health, clinical and social psychology. It is a phenomenological approach that explores how participants make sense of their personal and social worlds. The main focus for an IPA study is the meanings particular experiences and events hold for participants (Smith \& Osborn, 2008). However, in addition to the aim of getting close to the participant's worlds, IPA also attempts to make sense of the participant's world through a process of interpretative activity (Smith \& Osborn, 2008), and thus is epistemologically rooted in both phenomenology and hermeneutics (i.e., the theory of interpretation). IPA is a strongly idiographic research approach that is concerned with the detailed analysis of one case in detail which may be an end in itself (Smith et al. 2009).

Data was collected through semi-structured interviews. An interview schedule was constructed by the researchers, with reference to relevant literature and IPA guidance (Smith et al. 2009). The interview questions explored aspects of the parents' experiences, ranging from broad questions such as 'Can you tell me about your experience of abuse within your family or relationships?' to more specific questions such as 'In what way have your experiences of abuse impacted on you?' As per IPA guidance, the schedule allowed additional questions to follow unexpected responses. Interviews lasted an average of 60 minutes and, with consent, were audio-recorded and transcribed by the first author.

The data analysis employed the IPA procedure outlined by Smith and Osborn (2008) and comprised a number of stages. The first author began by listening to the audio recording and read the transcript a number of times. She noted anything that seemed relevant in relation to the participants' experience of abuse or violence from their children. Next, each transcript was re-read and emerging themes - topics or patterns that appeared repeatedly were noted in line with the first authors interpretation of the participants' own interpretative account. These were then summarised in a list, and the connections between 
the emerging themes and those that appeared thematically similar were clustered into groups. Next, the first author interpreted the core meaning of each group or cluster of emerging themes to assign a descriptive label. These represented the salient themes of each of the interviews. The second and third authors audited the documentation for three interviews as a validity check on the analysis. Once this process was completed, the first author also consulted with the fourth author as a final validity check on the analytic process. In the final stage of the analysis, the first author considered all the identified themes across the six transcripts and then developed a new, consolidated list of themes for the entire group, together with some illustrative extracts from the accounts. Next, this consolidated list of themes was examined by the first author and similarities and differences noted. Those themes that appeared to connect were clustered together into new themes and again checked against the original transcripts. The first three authors then considered this final list of themes, and eventually agreed on three superordinate themes that, based on their interpretation of the accounts, best described the participants' experience of violence or abuse from their children.

The research was approved by the $* * * * * * *$ Health and Human Sciences Ethics Committee ECDA and local Council Research Governance Framework boards. The Youth Justice Board authorised recruitment through regional YOTs. The results are presented without individually identifiable information to ensure confidentiality.

\section{Findings}

All of the parents recounted actual or threatened violence, occurring alongside or escalating from verbal abuse. Parents described being shoved, pushed to the floor, spat at, hit and kicked. Violence often targeted the home itself: walls and doors were smashed, and highvalue material possessions, such as cars, laptops and televisions, were taken, damaged or destroyed. Parents were often the victims of direct theft, and attempts were also made to coerce money from them. An extract from Helen's account (below) highlights the nature of the abusive encounters experienced by parents:

He snatched my handbag and was threatening to go in the handbag and help himself to the money. He ended up pushing me over and he was standing over me shouting, "Is this what you want you fucking stupid cow?" (Helen)

The Introduction to this article identified a number of complexities that are unique to adolescent-to-parent violence and abuse: the 'powerless' status of children relative to their parent(s); the parental responsibility that parents legally have for their children, which includes an element of criminal responsibility; the 'double stigma' that frames the culture of parent blame. These complexities produce a number of tensions and ambiguities which parents must navigate, and parents' articulation of these tensions and ambiguities constituted two superordinate themes within all of the parents' accounts. The third superordinate theme focused on how parents managed the acute emotional distress produced by attempting to manage these tensions and ambiguities in their everyday life. These three related themes are now presented, together with extracts from the participant accounts to support and illuminate them. 


\section{1) Tensions: "I'm frightened that I'm going to lose it"}

The key tensions that were central to the parents' accounts operated around wanting to resist their child but wanting to avoid violence; needing to distance themselves from their child while retaining parental proximity; wanting to unconditionally love their child but feeling unable to; and keeping themselves in control while feeling out-of-control.

Fear was central to all of the parents' accounts, especially anticipatory-fear and the consequent attempts to avoid inciting abusive behaviour. Parents repeated the common metaphor that they were "walking on eggshells", a phrase first described in the pioneering research in the 1970s that uncovered accounts of intimate partner violence and which has been echoed in other APVA research (see Holt, 2016). The emotional tension elicited by wanting to resist, yet also wanting to avoid further harm, was movingly articulated in Jenny's description of life with her daughter:

I have to give in because I don't want it. I'm frightened. I don't want to give in. I want to stick two fingers up and say "sod you". But I'm so frightened for myself. (Jenny)

Parents also spoke about their fear of loss as a result of their child's departure from the family home and their changed capacities to feel emotionally connected as a family. Parents' accounts drew on another emotional tension of needing to emotionally and physically distance themselves while also retaining responsibility and authority over their child. However, this tension was not always resolved in a balanced way, and Denise's account highlights her attempts to obliterate her son in her management of the harm caused:

When he moved out I didn't talk to him for two weeks cos I was infuriated with him. We redecorated when he moved out the other week. It just feels like l've got to wipe him out. I can't have him at home anymore. (Denise)

A further tension was articulated by all of the parents in their descriptions of the complicated love they had for their child. The unconditional love and affection parents had once felt was blurred by ambiguous emotions as the APVA progressed through the teenage years, as Jenny described:

As much as I love her dearly, with what we've been through that love has really turned bitter and I know she's my daughter but that love I had for her as a baby and as a child and even as in early teenage years is slowly dwindling. (Jenny)

Most strikingly, several parents described the emotional tension between retaining control as a 'good parent', and losing control and retaliating in response to extreme provocation:

I'm going to be brutally honest now. I'm frightened that I'm going to lose it...just beat the shit out of her really. I think I would just go over that mark as a parent....and see her as an object or as a threat. I don't think I could. But I think that someone just pushes your buttons and you just snap. (Jenny).

The tensions experienced and managed in the home also spilled over into the interview setting. During the interviews, parents initially presented themselves as emotionallycontained and disconnected. However, as the interviews progressed, there were episodes of anger, profanity and tearfulness as the phenomenon (the lifeworld as experienced) and the 
interpretation (the lifeworld as described) could not be disentangled. As Helen movingly articulated during a moment of reflection, this may produce a further tension through fear of being subsumed by the phenomenon and losing her sense of self:

I don't want my life to be defined as the woman who's living in fear of her son. (Helen)

The significance of the parents' sense of self to the parents' management of living with APVA is a point to which we return.

2) Ambiguities: “they'd say we can't do anything because he hasn't done anything yet"

The ambiguities central to the parents' accounts involved uncertainty about the

acceptability of the abusive behaviour; ambiguity about the causes of the abusive behaviour; ambiguity about the seriousness of the abusive behaviour; and ambiguity about the identity of self and others.

All parents felt that their experiences of APVA were unheard and ignored, both at an interpersonal level and at an institutional level. This was particularly the case early on in the child's abusive trajectory, when parents' concerns were met with doubt and disbelief. One possible reason for this is because, as Helen described, the child's behaviour was "always on the edge of what was acceptable behaviour". As Cottrell (2001) recognises, there is ambiguity between aspects of adolescence (i.e., maturation, puberty), pathology (e.g., ADHD, Autistic Spectrum Conditions) and definitively abusive behaviours. That the phenomenon of APVA is developmental makes identifying a 'cut-off point' between acceptable and unacceptable behaviour difficult. Several parents accounted for the gradual escalation of problematic behaviour by alluding to parental thresholds and tolerances, as Richard describes:

We wouldn't fund it [cannabis] so we wouldn't give him any money so then things would go missing. I mean I just you think that you're doing everything for them and then you're being paid back by [his son] doing things like that. We've always had problems but it just escalated from there (Richard)

Furthermore, several parents described each abusive episode as happening suddenly and shockingly, using metaphors such as "a flip of a coin" and "a dramatic turnaround". The ambiguity as to the cause of an abusive episode contributed to parents' sense of powerlessness, with there being "no rhyme or reason for it". In not being able to explain or comprehend their reality, parents seemed less prepared to seek help from others. All parents recounted the lengthy decision-making process of reporting their experiences to services, and sought advice from friends and family:

I spoke to a couple of mates and they advised against it [calling the police]. In hindsight I probably should have rung them but then it probably wouldn't have made any difference anyway. (Richard)

The ambiguous reality of APVA is also captured in Tina's account of calling the police, whose interpretation of whether something 'had happened' ran counter to Tina's interpretation: 
When I knew it was going to escalate I would call the police. Then they'd come out they'd say well we can't do anything because he hasn't done anything yet. But then I knew if they didn't arrest him or do something it's going to escalate. And then it did. (Tina)

The ambiguity of APVA was also drawn on in Helen's account, where her attempt to have the violence recognised as such was initially trivialised as a 'domestic quarrel' by the police:

At first the policewoman refused to take it seriously. She said it was a domestic quarrel and there was absolutely nothing she could do about it. I felt I'd been assaulted in my own home because he had pushed me over...so later she came back and re-interviewed me and took it seriously and they recorded it as an incident of domestic violence. (Helen)

The ambiguity of the phenomenon can, in time, extend to an uncertainty about who the parent is, and who their significant others are. For Tanya, who described her son as being "different" and "challenging" from early childhood, shame and judgement from others who were unable to relate to her parenting experiences left her questioning others' interpretations of her:

...they don't want to hear it anymore I suppose. The futility. The groundhog day of it all and the fact that they think that I just sit back and take it all. I don't think they know me. (Tanya)

Such ambiguities added to the parents' sense of isolation. As Tanya concluded:

My son's condition took over a lot of my life. I've kind of forgotten about me along the way so I've become very insular. (Tanya)

All of the parents described feeling alone and without support, both prior to and during the onset of the abuse, something that is consistent with prior research (Holt, 2011). All of the parents wanted to feel supported, practically and emotionally, by their partner, family, friends, and/or professional agencies, yet all reported feeling that their support needs, particularly in terms of repairing their relationship with their child, were left unmet. Three of the parents parented alone, and the married parents had experienced ruptures within their intimate relationship, describing their partner as "adding fuel to the fire" and "always the shadow". Where abuses were mainly directed at the other parent, there was a sense of "feeling like the person in the middle". Such vivid accounts highlight how, despite sharing a child who exhibits problematic behaviour, parents do not necessarily share the same experience, leaving parents who are commonly described as 'parenting together' feeling very alone.

3) Managing the harms: "Maybe two, three years this will all be underneath the carpet"

The tensions and ambiguities produced by APVA were clearly emotionally painful for parents, and the consequences for parents were severe, as Tanya recounted:

I got diagnosed with depression and post-traumatic stress disorder. I got it explained to me by saying because you're in a heightened state of awareness all of the time and its gone over a long period of time you just jump at anything now. (Tanya) 
Parents described multiple and varied strategies to cope with the emotional distress caused by their situation, including: taking medication; seeking clinical diagnoses for their children; minimising and/or normalising the child's behaviour; finding peer support through youth offending services; and finding solace within other aspects of their identity.

Many of the strategies that parents described were unhealthy and unsustainable. For example, all of the mothers described seeking help from their GP for their child, but instead received curative support for themselves in the form of medication or psychotherapy. For Denise, this resulted in a reliance on the numbing effects of medication to avoid emotional pain:

It's hard to bring feelings and emotions in because that's what the tablets that I' $m$ taking stops, and I don't want to come off them cos I won't be able to cope with it. (Denise)

The ambiguity of their child's behaviour in the context of 'normal' adolescence meant that parents attempted to understand their child's behaviour through the lens of pathology and disorder. Parents described searching for an underlying cause, with accounts of attending medical and CAMHS appointments, and seeking advice and support from education and youth offending services. Most parents viewed the problem as located within the child, identifying singular or multiple diagnoses to explain behaviour, most commonly ADHD, but also Autism, Specific Learning Disabilities, Oppositional Defiant Disorder and Conduct Disorder. Such diagnoses provided emotional relief for parents. For example, Tanya described how her son's amassed diagnoses helped her to cope with his behaviour and with the preservation of her parental identity:

\begin{abstract}
He got diagnosed with conduct disorder and oppositional defiant disorder. So they kept adding D's [disorders]. If he'd have had one more diagnosis at an earlier age maybe he would have not been so let down later on...(...)... I spent most of his childhood trying to prove he was....because to most people it's just 'bad parents'...I was almost vindicated. To me it was a relief. (Tanya)
\end{abstract}

A child's diagnosis is often comforting to parents experiencing APVA: it may enable access to support and resources, it may reposition blame from the parent and the child onto 'the disorder' and it may help provide a new 'spectrum of normality' against which parents can evaluate their experiences. For example, a diagnosis of ADHD enabled Denise to reconceptualise her son's violence as his 'normal', albeit delayed, transition into adulthood:

He's at a vulnerable age because the ADHD children, all their hormones are delayed. He was always behind with puberty at school so whereas the boys who'd turned into young men, he was just a kid. Where parents are going through hormonal stuff at 13,14, we've gone through it at 17,18 . (Denise)

Similarly, once Richard's son received a diagnosis of ADHD, his son's violence and abuse could be conceptualised as a 'normal' symptom of his pathology:

I mean some of his ADHD symptoms were quite bad. Violence and breaking things...you know. The normal sort of ADHD symptoms. (Richard)

Similarly, along with the other parents, Richard also exhibited a tendency to regulate his emotions by rationalising his child's behaviour and minimising its impact, often making comparisons between his son's current behaviour and what it could be, as Richard explains: 
Most of it is financial. He breaks things and sells things and steals things so yeah I've been disappointed and angry but it's just material goods isn't it. He's hurt us like that...he hasn't hurt us physically so we just get on and hope nothing else goes. (Richard)

Some parents sought help from statutory services. However, the tension between having to accept parental responsibility and living with continual violence, which is entrenched within organisational policies, is evident in Tina's account of seeking help from child social care services:

Well you can't win. You try to show your son that they can't behave like that and then the people who are meant to be helping you [social services] tell you that you aren't looking after him properly and are going to prosecute you if you don't take him home. It's horrendous. (Tina)

Other statutory services were described as being more helpful. For example, the YOTs' provision of confidential introductions to other abused parents meant that parents could offer empathic support to each other:

Meeting mums with not your average kids...these were extreme parenting kids...the support from other parents going through similar things was probably the best thing that came cos you feel very alone. (Tanya)

Several parents also described the importance and value of confidential psychotherapeutic services in helping them to manage the APVA, which included counsellors, psychologists and multi-systemic therapists:

I have more tactics to work things through. You know, I've different strategies, to have a different way of thinking if someone's in your face. That's through counselling. I've had CBT therapy. Doctors...you know... been helping me...but it's going to take time. (Jenny)

However, although most parents described the benefits of supportive services, many recognised that there were limits as to what they could offer. For example, Helen's account of her experience of multi-systemic therapy questioned the suitability of family-based interventions where the child remains ambivalent to the need for change:

You know ideally we as a family should all meet with [multi systemic therapist] but [my son] won't meet with her and she says try this and try that and we try it and then we have to come back and tell her what's happened...so you know we're struggling to make that work really to try and get something out of that. (Helen)

The confidential function of support was central to all accounts with parents only willing to disclose their experiences to those who were bound to secrecy, in effect mirroring parents' own shame and compulsion to hide. While several parents described feeling adequately supported, much of the support was experienced in the form of temporary relief from being out the family home and free from the identity position of 'parent':

I just needed to get out to be me. I don't feel like me at all...It's just nice to get out. Nice to be Denise and not mum. (Denise)

For other parents, other identities and roles outside the home performed the same function: 
Work is very important to me because it feels like the only part of my life that I know how to do right at the moment... (Helen)

The importance of identity was also underlined in parents' accounts of past and future selves. Across all accounts, parents reflected on their past and preferred futures, with and without abuse, and temporally positioned themselves at various 'stages of abuse'. Some parents described feeling like they were in the 'thick of the abuse' while other parents described a sense of overcoming the abuse. The concept of time was clearly important in parents' construction of APVA experiences and in their management of its harms. As Jenny's extract illuminates, this was achieved by mobilising a different future that would feature a different self:

I've still got a long way to go. But I'm nowhere where I was and that's what matters. All I have to do is look to the future and that's the only way I'm dealing with it at the moment...(...)... I just have a focus (Jenny)

\section{Discussion}

The analysis highlights how the tensions and ambiguities inherent within the phenomenon of APVA are experienced and managed by parents. The tensions and ambiguities in their many forms reflect how we normatively construct parent and offspring; perpetrator and victim; normalcy and pathology; adolescence and adulthood. While these complexities have previously been described in theoretical accounts of APVA (e.g., Holt, 2013; Routt \& Anderson, 2014), this is the first study to identify their articulation in parents' accounts, and for us to understand the harms they cause when they intersect in everyday life. Parents attempt to manage these harms in a number of ways. Some of these strategies are arguably unhealthy and unsustainable (e.g., taking medication, minimising/rationalising the abuse), while other strategies are more positive, and are potentially transformative (e.g., finding peer support through collective endeavour, finding relief in other identities and roles). However, none of the strategies serve to stop the violence and abuse in the family home, in keeping with international research (REF).

Further empirical examination of the complexity of family violence would be useful, and the application of methods that provide space for such tensions and ambiguities to manifest, such as IPA, would seem appropriate in and beyond the UK research sphere. To our knowledge, only two other published studies have examined APVA using IPA, both from New Zealand. A study by Williams et al. (2016) identified three superordinate themes of 'feelings', 'judgments' (by self and others) and 'the absence of a father figure'. A second study by Murphy-Edwards and van Heughten (2015) specifically focused on propertyviolence and identified three superordinate themes of 'impacts', 'coping strategies' and 'making sense of the abuse'. While tensions and ambiguities are implicit in both of these studies, neither of them attempted to articulate them as central themes around which parental anxieties and harms coalesce. Certainly this is in keeping with an IPA approach that is strongly descriptive. However, IPA analysts have been accused of overly describing a phenomenon at the expense of interpreting it (e.g., see Brocki \& Wealden, 2006), and we hope that our analysis highlights not only the patterns identified across parents' experiences, but also the broader significance of them in relation to their meanings and implications. 
Implications for practitioners

Findings from this study confirm findings from the international literature that APVA is a serious social problem that produces significant harms for parents (e.g. Cottrell, 2004;

Howard and Rottem, 2008). Furthermore, as found elsewhere, the parents interviewed here need more support, particularly around ending the abusive and violent behaviour. However, it is likely that this will only become realised when APVA is recognised and recorded as an unambiguous form of 'family violence' which, like other forms (i.e., intimate partner violence, child abuse) is socially and institutionally recognised as being unacceptable. Similarly, the tensions that shape parents' experiences of APVA need to be traced back to institutional policies and practices that leave parents in a 'no win' situation. The findings

underline the need to raise awareness of APVA at a global level, and across parenting and family communities, support services and agencies (e.g. police, courts, youth justice, mental health) and wider online and offline support networks (e.g., family, friends, neighbours and employers). As this research consistently found, the ambiguous and conflicting nature of APVA means that parents are often unable to recognise what is happening to them, do not have the language to name their experience, and do not know how or where to seek help, adding to their sense of isolation. Practitioners might be supported through training and professional development to increase their awareness of APVA and to hold in mind its inherent complexity that may serve to shield 'obvious markers' of its existence. 'Expertpatients' or service users could be recruited to support training providers to raise empathy and awareness among professionals which may hold research value

Given the role of family support agencies within these parents' accounts of help-seeking, the findings are particularly pertinent for professionals who may encounter parents early into the abuse trajectory and who will be central to the process of helping parents to disclose their experience and identify their support needs. Addressing their support needs may not require very much: in her synthesis of the international literature regarding what parents find most helpful in support programmes, Holt (2013) identified five key common elements: naming the abuse; listening to other parents' experiences; developing strategies to establish boundaries with young people; developing self-care strategies; and awarenessraising about the power dynamics of APVA. It is clear how each of these elements go some way to addressing the tensions and ambiguities identified in this article through the articulation of parents' experiences.

While some may claim that the small sample size of six is a limitation of this research, the data presented here remains in line with IPA aims of saying something 'substantive and specific' about the few participants in question (Smith et al. 2009). We do not know yet whether parents who experience APVA represent a 'small homogenous population' which Smith (1999) claims is particularly appropriate for IPA analysis. We fear that APVA may be a bigger problem, and may impact larger populations, than has yet been recognised. Clearly, there is a need for researchers to produce more robust prevalence data on APVA than we have at present, but as indicated earlier, this is unlikely to be produced while APVA is surrounded by tensions and ambiguities which prevent even parents themselves from recognising and reporting their experience. Thus, there is perhaps an even greater need for rich, detailed qualitative research that listens to parents' experiences and tries to determine 
what the phenomenon really involves: how it is experienced and how it is interpreted, by parents and others. IPA seems uniquely placed to enable researchers to do this. 


\section{References}

Agnew, R. and Huguley, S. (1989) Adolescent violence towards parents. Journal of Marriage and the Family, 51, 699-711.

Barker, C., Pistrang, N., \& Elliot, R. (2011) Research Methods in Clinical Psychology: Second $E d$. Cirencester: John Wiley and Sons.

Bentham, M. (2013) Children are beating parents, warns CPS boss. London Evening Standard, October 4 2013. Available from:

http://www.standard.co.uk/news/crime/children-are-beating-parents-warns-cps-boss8858860.html

Brocki, J. M., \& Wearden, A. J. (2006) A critical evaluation of the use of interpretative phenomenological analysis (IPA) in health psychology. Psychology and Health, 21(1), 87108.

Bobic, N. (2004) Adolescent Violence Towards Parents. Rosemount: Australian Domestic and Family Violence Clearinghouse.

Calvete, E., Gámez-Guadix, M. \& Orue, I. (2014) Características familiares asociadas a violencia filioparental en adolescentes [Family characteristics associated with childparent violence in adolescents]. Anales de Psicología, 30(3), 1176-1182.

Children Act 1989 (c.41) http://www.legislation.gov.uk. Retrieved 29 May 2016

Condry, R. \& Miles, C. (2012) Adolescent to Parent Violence and Youth Justice in England and Wales. Social Policy and Society, 11(2), 257-275/

Condry, R., \& Miles, C. (2013) Adolescent to parent violence: Framing and mapping a hidden problem. Criminology and Criminal Justice, $0(0), 1-19$.

Cottrell, B, \& Monk, P. (2004) Adolescent-to-Parent Abuse: A Qualitative Overview of Common Themes. Journal of Family Issues, 25(8), 1072-1095.

Cottrell, B. (2004). When teens abuse their parents. Fernwood Publishing

Cottrell, B. (2001) Parent abuse: The abuse of parents by their teenage children, Ottawa, Canada: Family Violence Prevention Unit, Health Canada.

Crime and Disorder Act 1998

(c.37)http://www.legislation.gov.uk/ukpga/1998/37/contents/enacted. Retrieved 10 June 2016

Downey, I., \& Furnish, K. (2015) Parenting a Violent Child. London: Darton Longman and Todd. 
Du Bois, R.H. (1998) Battered parents: psychiatric syndrome or social phenomenon? In A.Z. Schwarzberg (Ed.) The Adolescent in Turmoil (pp 124-33). Westport, CT: Paeger Trade.

Eckstein, N. J. (2004) Emergent Issues in Families Experiencing Adolescent-to-Parent Abuse. Western Journal of Communication, 68(4), 365-388.

Family Lives. (2011) When Family Life Hurts: Family Experience of Aggression in Children An update to Family Lives' October 2010 report [online]. Available from:

http://www.familylives.org.uk/media manager/public/209/Documents/Reports/the agg ression_report 2011 family lives.pdf

Gallagher, E. (2004) Parents victimized by their children. Australian and New Zealand Journal of Family Therapy, 25, 1-12.

Holt, A. (2009) Parent abuse: some reflections on the adequacy of a youth justice response. Internet Journal of Criminology, 1-9. Available from:

http://www.internetjournalofcriminology.com/holt parent abuse nov 09.pdf

Holt, A. (2011) "The terrorist in my home": teenagers' violence towards parents constructions of parent experiences in public online message boards. Child and Family Social Work, 16(4), 454-463.

Holt, A. (2012) Researching Parent Abuse: A Critical Review of the Methods. Social Policy and Society, 11(2), 289-298.

Holt, A. (2013) Adolescent-to-Parent Abuse: Current Understandings in Research, Policy and Practice. Bristol: Policy Press.

Holt, A. (2015) Adolescent-to-Parent Abuse as a Form of "Domestic Violence": A Conceptual Review. Trauma, Violence and Abuse. 1-10.

Holt, A. (2016) Working with Adolescent Violence and Abuse towards Parents: Approaches and Contexts for Intervention (Ed.). Oxon: Routledge.

Holt, A., \& Retford, S. (2013) Practitioner accounts of responding to Parent Abuse - a case study in ad hoc delivery, perverse outcomes and a policy silence. Child and Family Social Work, 18(3), 365-374.

Home Office. (2015) Information guide: adolescent to parent violence and abuse (APVA) retrieved on $24^{\text {th }}$ March 2015 from:

https://www.gov.uk/government/uploads/system/uploads/attachment data/file/420963/A PVA.pdf

Howard, J., \& Rottem, N. (2008) It All Starts at Home: Male Adolescent Violence to Mothers. A Research Report. Melbourne: Inner South Community Health Services Inc. 
Hunter, C., and Piper, C. (2012) Parent Abuse: Can Law Be the Answer? Social Policy and

Society, 11(2), 217-227.

Jackson, D. (2003) Broadening constructions of family violence: mothers 'perspectives of aggression from their children. Child \& Family Social Work, 8, 321-329.

Jackson, D., \& Mannix, J. (2004) Giving voice to the burden of blame: A feminist study of mothers' experiences of mother blaming. International Journal of Nursing Practice, 10, 150-158.

Laing, M. (2014) The Dark Side of Parenting: The Victim Experience of Parent Abuse. Massey University, Palmerston Noth, New Zealand, Unpublished MSc dissertation.

LaPorte, L., Jiang, D., Pepler, D.J., and Chamberland, C. (2009) The relationship between adolescents' experience of family violence and dating violence. Youth and Society, 43 (1), 3-27.

Laurent, A., \& Derry, A. (1999) Violence of French adolescents toward their parents: characteristics and contexts. Journal of Adolescent Health, 25 (1), 21-6.

Murphy-Edwards, L., \& van Heugten, K. (2015) Domestic Property Violence, A Distinct and Damaging Form of Parent Abuse. Journal of Interpersonal Violence, published online November 17th 2015

Nixon, J. (2012) Practitioners constructions of parent abuse. Social Policy and Society, 11 (2), 229-39.

O'Leary, K.D., Malone, J., and Tyree, A. (2004) Physical aggression in early marriage: prerelationship and relationship effects. Journal of Consulting and Clinical Psychology, 62 (3), 594-602.

Paterson, R., Luntz, H., Perlesz, A., \& Cotton, S. (2002) Adolescent Violence towards Parents: Maintaining family connections when the going gets tough. The Australian and New Zealand Journal of Family Therapy, 23(2), 90-100.

Pagani, L.S., Tremblay, R.E., Nagin, D., Zoccolillo, M., Vitaro, M., \& McDuff, P. (2004) Risk factor models for adolescent verbal and physical aggression toward mothers. International Journal of Behavioral Development, 28 (6), 528-537.

Pagani, L., Tremblay, R.E., Nagin, D., Zoccolillo, M., Vitaro, F., and McDuff, P. (2009) Risk factor models for adolescent verbal and physical aggression toward fathers. Journal of Family Violence, 24 (3), 173-182.

Parentline Plus. (2010) When Family Life Hurts: Family Experience of Aggression in Children, London: Parentline Plus.

Phares, V. (1992) Where's poppa? The relative lack of attention to the role of fathers in child and adolescent psychopathology. American Psychologist, 47 (5), 656. 
Routt, G., \& Anderson, L. (2014) Adolescent Violence in the Home: Restorative Approaches to Building Healthy, Respectful Family Relationships. London: Routledge.

Smith, J.A. (1999) Identity development during the transition to motherhood: An interpretative phenomenological analysis. Journal of Reproductive and Infant Psychology, 17 (3), 281-299.

Smith, J.A., Flowers, P., \& Larkin, M. (2009) Interpretative Phenomenological Analysis: Theory, Method and Research. London: Sage.

Smith, J. A., \& Osborn, M. (2008) Interpretative Phenomenological Analysis. In J. A. Smith (Ed.), Qualitative Psychology: A Practical Guide to Research Methods. London: Sage ( $2^{\text {nd }}$ ed).

Stanko, E.A. (2003) The Meanings of Violence. London: Routledge.

UK Government (2014, 11 12). Youth Offending Teams. Retrieved from GOV.UK: https://www.gov.uk/youth-offending-team

Williams, M. Tuffin K., \& Niland, P. (2016) "It's like he just goes off, BOOM!": mothers and grandmothers make sense of child-to-parent violence. Child and Family Social Work, published online 4 Feb 2016 